\title{
Mathematical Modeling on Two Phase Hepatic Systolic Blood Flow through arteries due to Hepatitis A
}

\author{
J. P. Singh ${ }^{1}$, A. K. Agrawal $^{2}$,V. Upadhyay ${ }^{3}$ and P. N. Pandey ${ }^{4}$ \\ ${ }^{1}$ Research Scholar, Dept. of Physical Sciences, M. G. C. Gramodaya Vishwavidyalay, Chitrakoot, Satna (M.P.), \\ India \\ ${ }^{2,3}$ Associate Professor, Dept. of Physical Sciences, M. G. C. Gramodaya Vishwavidyalay, Chitrakoot, Satna \\ (M.P.), India \\ ${ }^{4}$ Department of Mathematics, University of Allahabad. (U.P.), India
}

\begin{abstract}
The study of mathematical model of two phase blood flow in artery presented here. P.N. Pandey and V. Upadhyay have considered the blood flow has two phased, one of which is that of red blood cells and other is plasma. They have also applied the non-Newtonian power law model in bio fluid mechanical set-up. We have collected a clinical data in the case of Hepatitis A. The overall presentation is in tensorial form and solution technique adapted is analytical as well as numerical. The role of Hematocrit is explicit in the determination of blood pressure in case of Hepatitis A infection. The graphical presentation for particular parametric value is much closer to the clinical observation.
\end{abstract}

Keywords: Hepatitis A, Hematocrit, Hepatic Blood Flow, non-Newtonian power law model, circulatory system, Liver.

\subsection{Structure and Function of Liver:}

\section{Introduction}

Liver is the largest solid organ in the human body. In adult, the liver weight up to 1.5 kilograms. It is located in the upper right corner of the abdomen. The liver is a part of the digestive system. Within the liver, the portal veins divides into successive generations down to the interlobular veins, each of which is accompanied by a branch of the hepatic artery. The interlobular veins divides into portal venues from where the blood is distributed into the sinusoids. Sinusoids are small interconnected vessels transporting the blood toward terminal hepatic venues (also called centrilobular veins). The terminal hepatic venules unite in successive generations to form the hepatic veins, which leave the liver and empty into the inferior vena cava.The liver can be divided into functional units called lobules. The liver has 2 main lobes: the larger right lobe and smaller left lob. Each lobe is divided into segments. The lobes are separated by a band of tissue called the falciform ligament, which help attach the liver to the diaphragm. Liver lobes are surrounded by a thick capsule, mostly overlaid with reflected periforinum [1].
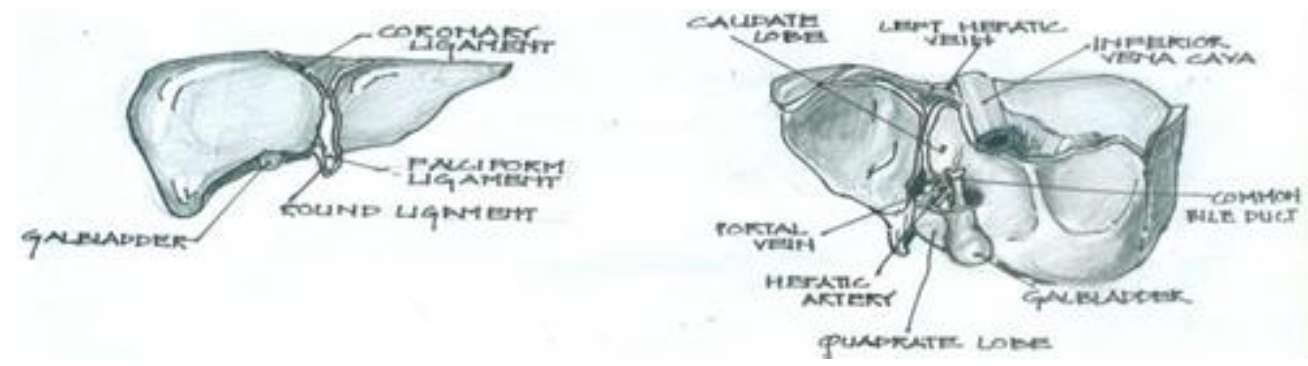

Figure 1.LiverStructures

According to the anatomical peculiarity of the double afferent blood supply of the liver, $75 \%-80 \%$ of the blood entering the liver is partially deoxygenated venous blood supplied by the portal vein, which collects all the blood that leaves the spleen, stomach, small and large intestine, gallbladder and pancreas[3-4]. The hepatic artery account for the remaining $25 \%$ with well-oxygenated blood. Total hepatic blood flow ranges between 800 and $1200 \mathrm{~mL} / \mathrm{min}$, which is equivalent to approximately $100 \mathrm{~mL} / \mathrm{min}$ per $100 \mathrm{~g}$ liver weight [5]. Although the liver mass constitutes only $2.5 \%$ of the total body weight, the liver receives nearly $25 \%$ of the cardiac output.

Although only limited data exist, it appears that hepatic blood volume ranges from 25 to $30 \mathrm{~mL} / 100 \mathrm{~g}$ liver weight, and accounts for $10 \%-15 \%$ of the total blood volume [6].Furthermore, rough estimation suggests that more than $40 \%$ of the hepatic blood is held in large capacitance vessels (portal vein, hepatic artery and 
hepatic veins), while the sinusoids accommodate up to $60 \%$.As small vessel content [5].Of note is the high compliance of the hepatic vascular bed, calculated as the change in blood volume per unit change in venous pressure [7].

\subsection{Structure and Function of Hepatic Artery:}

The common hepatic artery is one of the final branches of the celiac artery. It supplies oxygen-rich blood to the liver, pylorus, pancreas, and duodenum. It runs on the right inside the lesser sac, a cavity near the middle of the abdomen, and enters the lesser omentum, a folded membrane that attaches the stomach to the liver. The artery then passes upward toward the portahepatis, a deep groove in the back of the liver through which many neurovascular structures enter and leave the liver. The common hepatic artery splits into the proper hepatic artery and the gastroduodenal artery. The proper hepatic artery enters the portahepatis where it splits into the left and right hepatic arteries that supply the liver.As in any other artery of the body, oxygen saturation portal blood during the fasting state range up to $85 \%$, which is greater than that of other systemic veins; however, it substantially drop after food ingestion. It is generally accepted that $50 \%$ of the oxygen requirements of the liver are provided by portal venous blood and the other half derives from the hepatic artery [2].The liver normally receives more oxygen than it requires, and it can extract more oxygen to compensate for reduced delivery [8].The hepatic arterial blood flow was on the average 35\% of the hepatic venous blood. The function of the hepatic artery has been extensively studied in animals [9-13]. Great differences have been found from one species to another [14, 15], and our knowledge of the significance of the arterial blood supply to the human liver is limited mainly to observations of the late effect of occlusion of the hepatic artery [16] or the portal veins [17, 18].The liver volume and portal blood flow decreases after the age of50 [19].

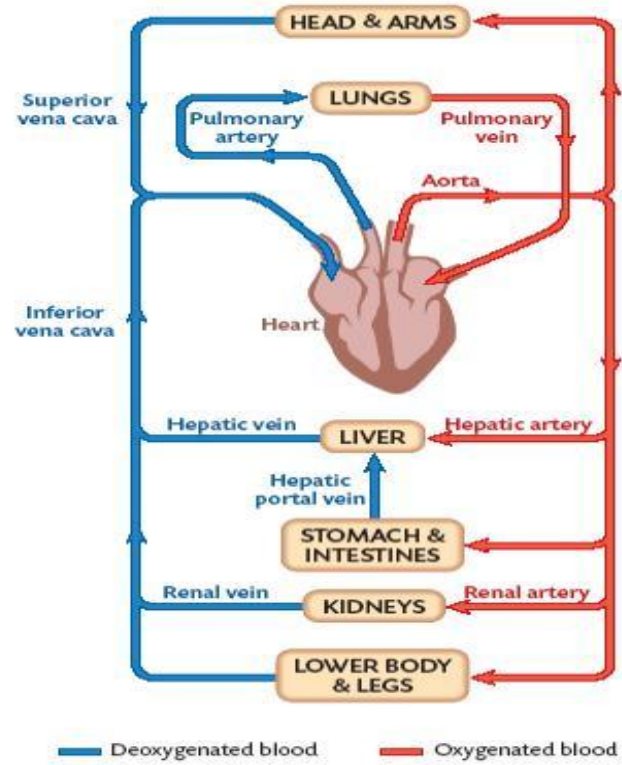

Figure 2.Hepatic blood flow

\subsection{Constitutions of Blood:}

Blood is specialized body fluid in human that delivers necessary substances such as nutrients and oxygen to the cells and transports metabolic waste products away from those cells. It is composed of blood cells suspended in a liquid called blood plasma. Plasma which constitutes 55\% of blood fluid is mostly water (92\% by the volume) [20]. Blood account for 7\% of the human body weight [21, 22]. By volume, the red blood cells constitute about $45 \%$ of whole blood, the plasma about $54.3 \%$ and white cells about $0.7 \%$ [23]. Whole blood (plasma and cells) exhibits non-Newtonian fluid dynamics. Red blood cells contain the blood's hemoglobin and distribute oxygen [24]. White blood cells are the part of the body's immune system. They destroy and remove old or aberrant cells and cellular debris as well as attack infection agents [25].Thrombocytes also called platelets; thrombocytes are responsible for blood clotting about 55\% of blood is blood plasma a fluid that is the blood's liquid medium, which by itself is straw-yellow in color. The percentage of volume covered by blood cells in the whole blood is called hematocrit. Two phase hepatic blood flow is a study of measuring the blood pressure if hemoglobin known. Hematocrit is is three times of hemoglobin concentration (reported as grams per deciliter) [26]. 


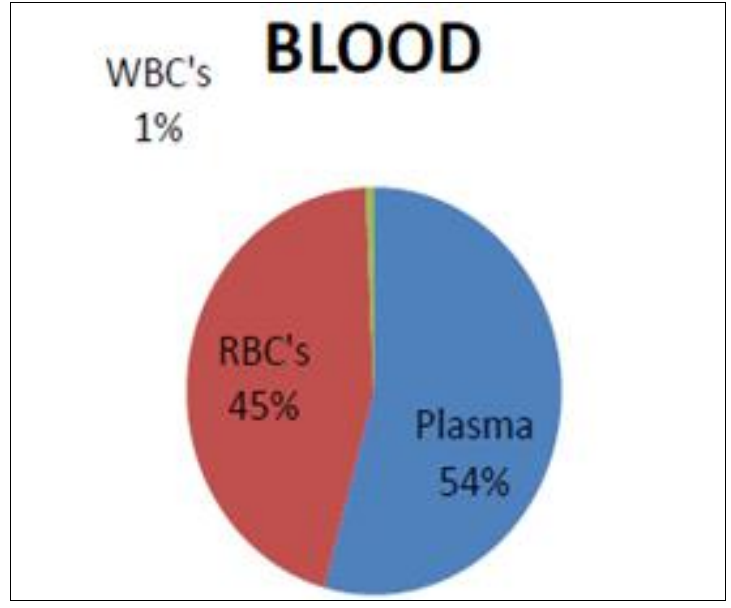

Figure. 3

Blood shows anomalous viscous properties. The anomalous behavior of blood is principally due to the suspension of particles in plasma. The two type of anomaly are due to 'low shear' and 'high shear' effect [27]. When blood flows through larger diameter fluid. The apparent viscosity of blood decreases with decreasing blood vessel diameter, when measurements are made in capillaries of diameter less than $300 \mu m$ [28]. This apparent dependence of viscosity on capillary radius is known as the Fahraeus-Lindqvist effect. But, when blood flow in smaller blood vessels of diameter $20 \mu \mathrm{m}-100 \mu \mathrm{m}$, the apparent viscosity increases as the blood vessel diameter decreases and it shows a non-Newtonian character. This non-Newtonian character of blood is typical in small arteries and veins where the presence of cells induces that specific behavior.

The analysis of two-fluid models for blood flow is better applied to small vessels such as femoral arteries carotid, coronaries, arterioles and very small arteries of diameter $130 \mu m-200 \mu m$ where the nonNewtonian effect are excepted to significant [29].The study of two-fluid models of Newtonian fluid, power law fluid and Bingham fluid can be possible by using this model as these fluid models are the particular cases of Herschel-Bulkley fluid model. Thus, in this paper, we study two phase model for systolic blood flow in hepatic artery due to hepatitis A.P.N. Pandey andV. Upadhyay (2001) discussed a some phenomena in two phase blood flow gave an idea on the two phase hepatic blood flow in artery with a liver disease Hepatitis A. The work of P.N. Pandey and V.Upadhyay in whole circulatory system but this work will be focus on Hepatic circulatory system, and Hepatic circulatory system is a sub system of whole circulatory system. In this work, applied the Herschel Bulkley non-Newtonian power law model.

\subsection{Description of Disease:}

Liver is also prone to many diseases [30]. One of these is Hepatitis A. Hepatitis A (formerly known as infectious hepatitis) is an acute infectious disease of the liver caused by the hepatitis A virus (HAV), an RNA virus, usually spread by the fecal-oral route; transmitted person-to person by ingestion of contaminated food or water or through direct contact with an infectious person. Tens of millions of individuals worldwide are estimated to become infected with HAV each year. The time between infection and the appearance of the symptoms (the incubation period) is between two and six weeks and average incubation period is 28 days. Hepatitis A, a term first introduced by Krugman et al. in 1967[31], is now known to be caused by infection with hepatitis A virus (HAV), one of five viruses, each belonging to a different family, whose primary site of replication is the liver.

\section{Hepatities A Virus}

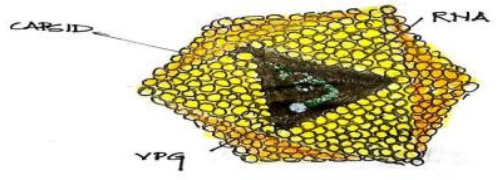

Figure 4. 
In 1973, HAV was identified in the stools of infected persons [32], which eventually led to development of diagnostic tests, propagation in cell culture, molecular characterization, and development of a vaccine [32, 33]. HAV is a no enveloped RNA virus 27 to $32 \mathrm{~nm}$ diameter in size, with an icosahedral symmetry, which belongs to the genus Hepatovirus of the Picornaviridae family. Unlike other members of the family, HAV requires a long adaptation period to grow in cell culture, replicates slowly, and rarely produces acytopathic effect $[34,35,36]$. HAV is stable in the environment for at least 1 month [37] and is more resistant to heating and chlorine inactivation than is poliovirus. Inactivation of HAV requires heating foods to greater than $85^{\circ} \mathrm{C}$ for $1 \mathrm{~min}$, and disinfection of surfaces requires $1 \mathrm{~min}$ of contact with a 1:100 dilution of sodium hypochlorite (i.e., household bleach), whereas poliovirus is inactivated at $72^{\circ} \mathrm{C}$ for $15 \mathrm{~s}$ and by treatment with a 1:125 dilution of bleach for $30 \mathrm{~s}$ [38, 39, 40]. In a 1998 report, Vento et al. [41] described a series of cases of fulminant acute hepatitis $\mathrm{A}$ in persons with chronic hepatitis $\mathrm{C}$, leading to the conclusion that acute hepatitis $\mathrm{A}$ superimposed on chronic hepatitis $\mathrm{C}$ in particular and on chronic liver disease (CLD) in general was likely to exacerbate the severity of acute hepatitis A, which otherwise was self-limited and generally mild to moderate [42].

\section{Real Model}

Blood is a complex fluid consisting of particulate curpusclees suspended in a non-Newtonian fluid.The particulate solid are red blood cells (RBCs), white blood cells (WBCs) and platelets. 50\% of the plasma and $45 \%$ of the blood cells in a whole blood and approximately $98 \%$ of RBCs in $45 \%$ of blood cells and there are a few parts (approximately 2\%) of the other cells. Which are ignorable, so one phase of the blood plasma and second phase of blood is RBCs.

Boundary conditions are as follows:

1. The velocity of blood flow on the axis of artery at $r=0$ will be maximum and finite, say $V_{0}$.

2. The velocity of blood flow on the wall of the blood vessels at $r=R$, Where, $R$ is the radius of traverse. Section of artery, will be zero. This condition is well known as no-slip condition.

The Newtonian power law equation- $\boldsymbol{\tau}=\boldsymbol{\eta} \mathbf{e}$ Where, $\boldsymbol{\eta}$ is the viscosity of coefficient [43]. This is found to hold good in broad blood vessels where there is low hematocrit.Pressure difference is a difference of pressure of two end points of the vessels. Let us consider in any blood vessels of hepatic circulatory system .Let $\mathrm{p}_{\mathrm{i}}$ represents the pressure at the origin of the vessels, at the other end point pressure is $p_{f}$. Then the pressure difference is represented by $\mathrm{p}_{\mathrm{i}}-\mathrm{p}_{\mathrm{f}}$ blood pressure of the first end point is greater than the blood pressure of other end point , that is

$\mathrm{p}_{\mathrm{i}}>\mathrm{p}_{\mathrm{f}}$

$\Delta \mathrm{p}=-\left(\mathrm{p}_{\mathrm{f}}-\mathrm{p}_{\mathrm{i}}\right)$

\section{Basic Bio-Fluid Equation For Two Phase Blood Flow}

Let us problem of blood flow in hepatic circulatory system is different from the problems in cylindrical tube and select generalized three dimensional orthogonal curvilinear coordinate system. Briefly described as $\mathrm{E}^{3}$ called as Euclidean space. According to Mishra the biophysical laws thus expressed fully hold good in any coordinate system which is a compulsion for the truthfulness of the laws [44].According to the Sherman I.W. and Sherman V.G. blood is mixed fluid [45]. Mainly there are two phases in blood. The first phase is plasma, while the other phase is that of the blood cells are enclosed with semi permeable membranes whose density is greater than that of plasma. These blood cells are uniformly distributed in plasma. Thus, blood can be considered as a homogeneous mixture of two phases [45].

\subsection{Equation of Continuity for two phase blood flow:}

The blood flow is affected by the presence of blood cells. This effect is directly proportional to the volume occupied by blood cells [46]. Let the volume portion covered by blood cells in unit volume be X, this X is replaced by $\mathrm{H} / 100$, where $\mathrm{H}$ is the Hematocrit the volume percentage of blood cells. Then the volume portion covered by the plasma will be $(1-\mathrm{X})$. If the mass ratio of blood cells to plasma is $\mathrm{r}$ then clearly $\mathrm{r}=\frac{\mathrm{x}_{\mathrm{p}}}{(1-\mathrm{x}) \mathrm{Pp}_{\mathrm{p}}}$

Where $\rho_{c}$ and $\rho_{p}$ are densities of blood cells and blood plasma respectively. Usually this mass ratio is not constant, even then it may be supposed to constant in present context [46].The both phase of blood, i.e. blood cells and plasma move with the common velocity. Campbell and Pitcher has presented a model for two phase of blood separately [47]. The equation of continuity for two phases according to the principle of conservation of mass defined by Kapur J. N. and Gupta R.C. [48] as follow: 
$\frac{\partial\left(\mathrm{X} \rho_{\mathrm{C}}\right)}{\partial \mathrm{t}}+\left(\mathrm{X} \rho_{\mathrm{c}} \mathrm{v}^{\mathrm{i}}\right)_{\mathrm{i}}=0$

$\frac{\partial(1-\mathrm{X}) \rho_{\mathrm{p}}}{\partial \mathrm{t}}+\left((1-\mathrm{X}) \rho_{\mathrm{p}} \mathrm{v}^{\mathrm{i}}\right)_{\mathrm{i}}=0$

Where, $v$ is the common velocity of two phase blood cells and plasma. If we define the uniform density of the blood $\rho_{m}$ as follow:

$\frac{1+r}{\rho_{\mathrm{m}}}=\frac{r}{\rho_{\mathrm{c}}}+\frac{1}{\rho_{\mathrm{p}}}$

From equation (3.2) and (3.3) we can written as,

$\frac{\partial \rho_{\mathrm{m}}}{\partial \mathrm{t}}+\left(\rho_{\mathrm{m}} \mathrm{v}^{\mathrm{i}}\right)_{\mathrm{i} \mathrm{i}}=0$

where $\rho_{m}=X \rho_{c}+(1-X) \rho_{p}$

\subsection{Equation of motion for two phase blood flow:}

The hydro dynamical pressure P between the two phases of blood can be supposed to be uniform because the both phases i.e. blood cells and plasma are always in equilibrium state in blood [49]. Taking viscosity coefficient of blood cells to be $\eta_{c}$ and applying the principle of conservation of momentum, we get the equation of motion for the phase of blood cells as follows:

$\mathrm{X} \rho_{c} \frac{\partial v^{1}}{\partial t}+\left(X_{\rho_{c}} v^{\mathrm{j}}\right) v_{\mathrm{j}}^{\mathrm{i}}=-\mathrm{Xp}_{\mathrm{j}} \mathrm{g}^{\mathrm{ij}}+\mathrm{X} \eta_{\mathrm{c}}\left(\mathrm{g}^{\mathrm{j} k} \mathrm{v}_{\mathrm{k}, \mathrm{j}}^{\mathrm{i}}\right)_{\mathrm{j}}$

The equation of motion for plasma will be as follows:

$(1-X) \rho_{p} \frac{\partial v^{1}}{\partial t}+\left\{(1-X) \rho_{p} v^{j}\right\} v_{j}^{i}=-(1-X) p_{i j} g^{i j}+(1-X) \eta_{c}\left(g^{j k} v_{d k}^{i}\right)_{j}$

Now adding equation (3.6) and (3.7) and using relation (3.4), the equation of motion for blood flow with the both phases will be as follows:

$\rho_{m} \frac{\partial v^{i}}{\partial t}+\left(\rho_{m} v^{j}\right) v_{j}^{i}=-p_{i j}+\eta_{m}\left(g^{j} k^{i} v_{k}^{i}\right)_{j}$

Where $\eta_{m}=X \eta_{c}+(1-X) \eta_{p}$ is the viscosity coefficient of blood as a mixture of two phases.

\section{Mathematical Modeling}

We consider the two layer blood flow to be Newtonian. The first layer is that of plasma while second one is core layer. Let the viscosity of plasma layer be $\eta_{p}$ and that of the core layer $\eta_{m}$ where $\eta_{\mathrm{m}}=\mathrm{X} \eta_{\mathrm{c}}+(1-\mathrm{X}) \eta_{\mathrm{p}}$ where $\eta_{\mathrm{c}}$ is the viscosity of the blood cells and $\mathrm{X}$ is portion of blood cells in unit volume.

Now the basic equation can be written in a similar way as before.Now we describe the basic equation for Power law blood flow as follows:

Equation of continuity in tensorial form as follows:

$\frac{1}{\sqrt{\mathrm{g}}}\left(\sqrt{\mathrm{g}^{\mathrm{i}}}\right)_{\mathrm{i}}=0$

Equation of motion:

$\rho_{m} \frac{\partial v^{i}}{\partial t}+\rho_{m} v^{j} v_{j j}^{i}=-\rho_{j j} g^{i j}+\eta_{m}\left(g^{j k} v_{j k}^{i}\right)_{j j}$

Where $\rho_{m}=X \rho_{c}+(1-X) \rho_{p}$, is the density of blood as mixture of blood cells and plasma. While $\eta_{m}=X \eta_{c}+(1-X) \eta_{p}$ is the viscosity of mixture of the blood. Other symbols have their usual meanings.

We have transformed in cylindrical form equation (4.1) and (4.2)

The blood flow in artery is symmetric w.r.t. axis. Hence, $v_{\theta}=0, v_{z}, v_{r}$ and $p$ do not depend upon $\theta$. Since only one component of velocity which is along the axis is effective.

We have, $v_{r}=0, v_{\theta}=0, v_{z}=v$

Since, flow is steady, we have [50]

$\frac{\partial \mathrm{P}}{\partial \mathrm{t}}=\frac{\partial \mathrm{v}_{\mathrm{r}}}{\partial \mathrm{t}}=\frac{\partial \mathrm{v}_{\theta}}{\partial \mathrm{t}}=\frac{\partial \mathrm{v}_{\mathrm{z}}}{\partial \mathrm{t}}=0$

Keeping in view these facts, we obtain the following result.Equation of continuity reduces to 


$$
\begin{aligned}
& \frac{\partial v_{z}}{\partial z}=0 \\
& \Rightarrow v_{z}=v(r)
\end{aligned}
$$

The r-component of equation of motion reduces to

$$
\begin{aligned}
& \rho_{\mathrm{m}}(0)=-\frac{\partial \mathrm{p}}{\partial \mathrm{r}}+\eta_{\mathrm{m}}(0) \\
& \Rightarrow \frac{\partial \mathrm{p}}{\partial \mathrm{r}}=0 \\
& \Rightarrow \mathrm{p}=\mathrm{p}(\mathrm{z})
\end{aligned}
$$

$\theta$-component of equation of motion reduces to

$$
\begin{aligned}
\rho_{\mathrm{m}}(0) & =0+\eta_{\mathrm{m}}(0) \\
\Rightarrow 0 & =0
\end{aligned}
$$

Similarly, the Z-component of equation of motion reduces to

$$
\rho_{\mathrm{m}} \mathrm{v}_{\mathrm{z}} \frac{\partial \mathrm{v}_{\mathrm{z}}}{\partial \mathrm{t}}=-\frac{\partial \mathrm{p}}{\partial \mathrm{z}}+\eta_{\mathrm{m}}\left[\frac{1}{\mathrm{r}} \frac{\partial}{\partial \mathrm{r}}\left\{\mathrm{r} \frac{\partial \mathrm{v}_{\mathrm{z}}}{\partial \mathrm{r}}\right\}+\frac{\partial^{2} \mathrm{v}_{\mathrm{z}}}{\partial \mathrm{z}^{2}}\right]
$$

With the help of equation (4.3) and (4.6) we get

$$
0=-\frac{\partial \mathrm{p}}{\partial z}+\left\{\frac{1}{\mathrm{r}} \frac{\partial}{\partial \mathrm{r}}\left(\mathrm{r} \frac{\partial \mathrm{v}(\mathrm{r})}{\partial \mathrm{r}}\right)\right\}
$$

whereas, the equation (3.4) expresses the fact that the pressure p depends only on $\mathrm{z}$. We also retain the fact that pressure gradient $-\frac{\partial p}{\partial z}$ in the arteries remote from the heart is constant, say $p$ then the equation (3.7) takes the following form

$0=\mathrm{P}+\eta_{\mathrm{m}}\left\{\frac{1}{\mathrm{r}} \frac{\partial}{\partial \mathrm{r}}\left(\mathrm{r} \frac{\partial \mathrm{v}(\mathrm{r})}{\partial \mathrm{r}}\right)\right\}$

Integrating the equation (4.8), we get,

$\mathrm{r} \frac{\mathrm{dv}}{\mathrm{dr}}=-\frac{\mathrm{pr}^{2}}{2 \eta_{\mathrm{m}}}+\mathrm{A}$

Where A be the constant of integration

Apply the first boundary condition on the equation (4.9), we get $A=0$

Hence equation (4.9) reduces to

$\mathrm{r} \frac{\mathrm{dv}}{\mathrm{dr}}=-\frac{\mathrm{pr}^{2}}{2 \eta_{\mathrm{m}}}$

Again integrating the equation (4.10), we get,

$v=-\frac{p^{2}}{4 \eta_{m}}+B$

Again using second boundary condition on the equation (4.11), we can evaluate the integration constant as follows:

$\mathrm{B}=\frac{\mathrm{PR}^{2}}{4 \eta_{\mathrm{m}}}$

Inserting the value of B in the equation (4.11), we obtain the velocity of blood flow in the arteries as follows:

$\mathrm{v}=\frac{\mathrm{P}}{4 \eta_{\mathrm{m}}}\left(\mathrm{R}^{2}-\mathrm{r}^{2}\right)$

\section{Result (Bio-Physical Interpretation)}


Observations: Hematocrit Vs blood pressure is taken from Santosh hospital Meerut(U.P.)

Patient name- Mr. Lokesh Sharma Age - 30 Years

Diagnosis-Dr. P.C. Sharma

\begin{tabular}{|l|l|l|l|l|}
\hline Date & HB in gm/dl & Systolic Blood pressure in mmhg & Hematocrit & Blood Pressure in Pascal \\
\hline $1 / 08 / 2015$ & 10.6 & 150 & 31.8 & 19998.36 \\
\hline $3 / 08 / 2015$ & 10.8 & 140 & 32.4 & 18665.13 \\
\hline $4 / 08 / 2015$ & 10.3 & 120 & 30.9 & 15998.68 \\
\hline $5 / 08 / 2015$ & 10.2 & 110 & 30.6 & 14665.46 \\
\hline $6 / 08 / 2015$. & 10.5 & 100 & 31.5 & 13332.24 \\
\hline
\end{tabular}

Table 1.

According to Berkow, Robert, The hematocrit (expressed as percentage points) is normally about three times the hemoglobin concentration (reported as grams per deciliter) [51].The Flow flux of blood in arteries is given bellow:

$$
\begin{aligned}
& Q=\int_{0}^{R} 2 \pi r v d r=\int_{0}^{R} \frac{P}{4 \eta_{m}}\left(R^{2}-r^{2}\right) 2 \pi r d r \\
& =\frac{P}{4 \eta_{m}}\left[\pi R^{2} r^{2}-\frac{\pi r^{4}}{2}\right]_{0}^{R} \\
& =\frac{\pi R^{4} p}{8 \eta_{m}} \\
& Q=\frac{\pi R^{4}}{8 \eta_{m}}\left(-\frac{d P}{d z}\right) \\
& \int_{z_{i}}^{z_{f}} Q d z=-\int_{p_{i}}^{p_{f}} \frac{\pi R^{4}}{8 \eta_{m}} d p \\
& Q\left[z_{f}-z_{i}\right]=\frac{\pi R^{4}}{8 \eta_{m}}\left[p_{i}-p_{f}\right] \\
& {\left[p_{i}-p_{f}\right]=\frac{8 \eta_{m}}{\pi R^{4}} Q\left[z_{f}-z_{i}\right]}
\end{aligned}
$$

Where,

$z_{f}-z_{i}=$ Length of arteries

Average $(\mathrm{H})=31.44 \mathrm{gm}$. $/ \mathrm{dl}$

Average $(\mathrm{BP})=16531.97$ Pascal

Average length of arteries $=0.05[52], \eta_{m}=0.035$ pa.s. and $\eta_{p}=0.0015$ pa.s.

Since, we know that

$$
\begin{aligned}
& \eta_{m}=\eta_{c} X+(1-X) \eta_{p} \\
& \eta_{c}=0.10805
\end{aligned}
$$

From equation (5.3)

$$
\begin{aligned}
& \eta_{m}=(0.10805-0.0015) \times \frac{H}{100}+0.0015 \\
& \eta_{m}=0.00107 H+0.0015
\end{aligned}
$$

From equation (5.2)

$$
\begin{aligned}
& \left(p_{i}-p_{f}\right)=\frac{8 \times 0.01833 \times 0.05}{3.14\left(2.5 \times 10^{-3}\right)^{4}} \eta_{m} \\
& \left(p_{i}-p_{f}\right)=\frac{7.332 \times 10^{-3}}{1.227 \times 10^{-10}} \eta_{m} \\
& \left(p_{i}-p_{f}\right)=59755501.22(0.00107 H+0.0015) \\
& \left(p_{i}-p_{f}\right)=89633.25+63938.39 H
\end{aligned}
$$

We get, values of blood pressure drop if hematocrit known by using above equation (relation between blood pressure drop and hematocrit) 
Mathematical Modeling on Two Phase Hepatic Systolic Blood Flow through arteries....

\begin{tabular}{|l|l|l|l|l|l|}
\hline $\begin{array}{l}\text { H (Hematocrit) } \\
\text { (g/dl) }\end{array}$ & 31.8 & 32.4 & 30.9 & 30.6 & 31.5 \\
\hline $\begin{array}{l}\text { P (Blood Pressure drop) } \\
\text { (Pascal) }\end{array}$ & 2122874.05 & 2161237.09 & 2065329.5 & 2046147.98 & 2103692.54 \\
\hline
\end{tabular}

Table 2.

Table 2 shows change in the blood pressure drop with increase in hemoglobin. The graph of above table is given in figure-5.

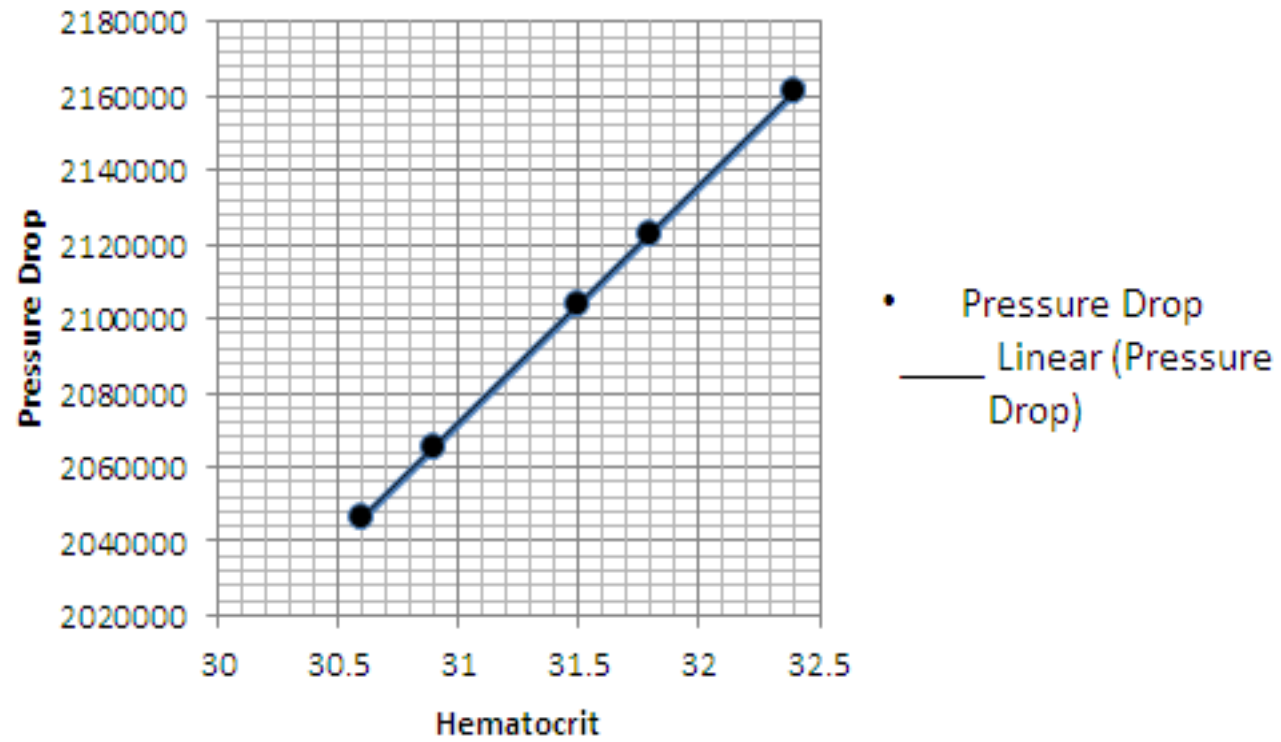

Figure 5.

\section{Conclosion}

A simple survey of the graph between blood pressure drop and hematocrit in figure 5 shows that when hematocrit increased then blood pressure also increased. That is Hematocrit proportional to Systolic blood pressure.

\section{Acknowledgement}

I give my sincere thanks to Dr. P.C. Sharma, Physician of Santosh Hospital, Meerut (U. P.), Dr. P. K. Srivastava, Assistant Professor, Galgotia College of Engineering \& Technology, Greater Noida(U.P), Dr. Kapil Tyagi,Assosiate Professor, GNIOT, Greater Noida, Dr. Shweta Tyagi, Associate Professor,GNIOT, Greater Noida, and Mr. Vidit Jain for valuable support.

\section{Remark}

If this would have been possible to get blood pressure on the particular tissue (liver) during operation of hepatitis A patient then the relation between blood pressure and hemoglobin has been measured more accurately.

\section{References}

[1] Berry A.K.,Kapoor A.S., NagabhushanamR , Animal physiology, 1981

[2] ]Vollmar B, Menger MD. The hepatic microcirculation, mechanistic contributions and therapeutic target in liver injury and repair. Physiol Rev 2009, 89: 1269-1339

[3] Schenk WG Jr, McDonald JC, McDonald K, Drapanas T. Direct measurement of hepatic blood flow in surgical patients: with related observations on hepatic flow dynamics in experimental animals. Ann Surg 1962; 156: 463-471

[4] Rappaport AM. Hepatic blood flow: morphologic aspects and physiologic regulation. Int Rev Physiol 1980; 21 : 1-63

[5] Greenway CV, Stark RD. Hepatic vascular bed. Physiol Rev 1971; 51: 23-65

[6] Lautt WW. Hepatic vasculature: a conceptual review. Gastroenterology 1977; 73: 1163-1169

[7] Lautt WW, Greenway CV. Hepatic venous compliance and role of liver as a blood reservoir. Am J Physiol 1976; 231: 292-295

[8] Bredfeldt JE, Riley EM, Groszmann RJ. Compensatory mechanisms in response to an elevated hepatic oxygen consumption in chronically ethanol-fed rats. Am J Physiol 1985; 248: G507-G511

[9] Burton-Opitz, R. The vascularity of the liver. I. The flow of blood in the hepatic artery. Quart. J. exp. Physiol. 1910, 3, 297.

[10] Barcroft, J., and Shore, L. E. The gaseous metabolism of the liver. Part I: In fasting and late digestion. J. Physiol. (Lond.) 1912, 45, 296. 
[11] Schwiegk, H. Untersuchungenuiber die Leberdurchblutungund der Pfortaderkreislauf. Naunyn- Schmiedeberg's Arch. exp. Path. harmak.1932, 168, 693.

[12] Blalock, A., and Mason, M. F. Observations on the blood flow and gaseous metabolism of the liver of unanesthetized dogs. Amer. J. Physiol. 1936, 117, 328.

[13] McMichael, J. The oxygen supply of the liver.Quart.J. exp. Physiol. 1938, 27, 73.

[14] Child, C. G., III. The Hepatic Circulation and Portal Hypertension. Philadelphia, Saunders, 1954,p. 196.

[15] Markowitz, S., Rappaport, A., and Scott, A. C. Prevention of liver necrosis following ligation of hepatic artery. Proc. Soc. exp. Biol. (N.1949, 70, 305 .

[16] Graham, R. R., and Cannell, D. Accidental ligation of the hepatic artery. Report of one case, with areview of the cases in the literature. Brit. J. Surg. 1933, 20, 566.

[17] Bradley, S. E., Smythe, C. M., Fitzpatrick, H. F., and Blakemore, A. H. The effect of a portacaval shunt on estimated hepatic blood flow and oxygen uptake in cirrhosis. J. clin. Invest. 1953, 32, 526.

[18] Gliedman, M. L., Sellers, R. D., Grant, R. N., Burkle, J. S., Leevy, C. L., and Vestal, B. L. Observations on the effect of portacaval astomosis upon the hemodynamics of the liver.Surg.Gynec.Obstet. 1959, 108, 223.

[19] Whynne HA, Cope LH, Mutch et al. The effect of age upon liver. 1989; 9:297-301.

[20] The Franklin Innstitute Inc., "Blood- The human Heart", retrieved 19 march, 2009.

[21] Alberts, Bruce, "Table 22-1 Blood cells"; Molecular Biology of the cell.NCBI Bookshelf; 1 November2012.

[22] Elert Glenn and his student, "Volume of blood in a human", The physics fact book, archived from the origin on 1 November 2012

[23] Shmukler, Michael,"Density of blood", The Physics fact book, 2004.

[24] "Medical Encyclopedia; RBC Count "; Medline plus; 18 November; 2007.

[25] Ganong, William F. ; Review of medical physiology (21 ed.), New York ; Lange Medical Books; Mc P. 518 ; 2003

[26] Berkow, Robert,ed. Merck Manual of Medical Information. Whitehouse Station, NJ:Merck Research Laboratories, 1997.

[27] S. Chien, S. Usami and R. Skalak, 1984, Blood flow in small tubes, In Renkins E. M., Michel C. C. (Eds), American Physiological Society Handbook of Physiology, Section 2, The Cardiovascularsystem, Vol. 4, Bethesda MD: American Physiological Society (1984) 217-249

[28] R. Fahraeus and R. Lindqvist, Viscosity of Bloodin Narrow Capillary Tubes, American Jour-nal Physiology, 96 (1931) 562-568.

[29] V. P. Srivastava and M. Saxena, Two-layered model of Casson fluid flow through stenotic blood vessels: applications to the cardiovascular system, Journal of Biomechanics, 27 (1994) 921-928.

[30] Cirrhosis overview: National Digestive Information clearing house, retrieved on 2010, 01-02.

[31] Krugman, S., J. P. Giles, and J. Hammond: Infectious hepatitis. Evidence for two distinctive clinical, epidemiological, and immunological types of infection, JAMA, 1967,200,365-373,

[32] Feinstone, S. M., A. Z. Kapikian, and R. H. Purcell; Hepatitis A: detection by immune electron microscopy of a virus-like antigen associated with acute illness; Science ; 1973,182;1026-1028;

[33] Provost PJ, HillemanMR.;Propagation of human hepatitis A virus in cell culture in vitro;ProcSocExpBiol Med; 1979.,160;213-221.

[34] Cromeans, T. L., M. O. Favarov, O. V. Nainan, and H. S. Margolis; Hepatitis A and E viruses. In Y. H. Hui, S. A. Sattar, K. D. Murrell, W.-K. Nip, and P. S. Stanfield (ed.), Foodborne disease handbook, 2nd ed., Viruses, parasite, pathogens, and HACCP; Marcel Dekker, New York, N.Y. $2001 ; 2 ; 23-76$.

[35] Hollinger, F. B., and S. U. Emerson; Hepatitis A virus, In D. M. Knipe and P. M. Howley (ed.), Fields virology, 4th ed. ;Lippincott Williams \& Wilkins, New York, N.Y.; 2001, 799-840.

[36] Lemon, S.M. Hepatitis A virus: Current concepts of the molecular virology, immunobiology and approaches to vaccine development;Review in Medical Virology; 1992, 2; 73-87.

[37] McCaustland, K. A., W. W. Bond, D. W. Bradley, J. W. Ebert, and J. E. Maynard; Survival of hepatitis A virus in feces after drying and storage for 1 month ;J. Clin. Microbiol;1982,16;957-958.

[38] Margolis, H. S.; Viral hepatitis, in R. B. Wallace and B. N. Doebbeling (ed.), Maxcy-Rosenau-Last Public Health and Preventive Medicine, 14th ed; Appleton \& Lange, Stamford, Conn.;2000,174-188.

[39] Strazynski, M., J. Kramer, and B. Becker/ Thermal inactivation of poliovirus type 1 in water, milk and yoghurt; Int. J. Food Microbiol; 2000,74;73-78.

[40] Weber, D. J., S. L. Barbee, M. D. Sobsey, and W. A. Rutala; The effect of blood on the antiviral activity of sodium hypochlorite, a phenolic, and a quaternary ammonium compound; Infect.Control Hosp. Epidemio;1999, 20; 821-827.

[41] Vento S, Garofano T, Renzini C, et al./ Fulminant hepatitis associated with hepatitis A virus superinfection in patients with chronic hepatitis C/ N Engl J Med1998/ 338/286 -290.

[42] Keeffe EB/Acute hepatitis $\mathrm{A}$ and $\mathrm{B}$ in patients with chronic liver disease: prevention through vaccination/ Am J Med/ 2005/118(Suppl 10A)/21S-27S.

[43] Taylor, M.G.: Hemodynamics.Ann.Rev.Physiol:1973,35:87.

[44] Mishra R.S. Tensors and Riemannian Geometry, Pothishala Pvt. Ltd. Allahabad, 1990.

[45] Sherman, I.W. \&Shernman V.G., Biology - A Human Approach Oxford Univ. press, New York, Oxford,1989, 278-79.

[46] Singh P. and Upadhyay K.S., a new approach for the shock propogation in the two phase system; NAT. acad. Sc. ; Letters, 1986,vol 8 , No 2 .

[47] Compbell, I.J. and picher A,S. , shock waves in a liquid containing gas bubbles, proc. Roy Soc; A243,1958

[48] Kapur J.N. and Gupta, R.C; Power law fluid flow in the inlet length of a circular pipe ; the math, seminar 1963, 3, ,55-67.

[49] Ruch, T.C and H.D , physiology and bio-physics, vols (ii) and (iii) W.B.S, 1973

[50] Kapur, J.N.; Mathematical models in biology \& Medicine, E.W.P. New Delhi;346;1992.

[51] Berkow, Robert, ed. Merck Manual of Medical Information. Whitehouse Station, NJ: Merck Research Laboratories, 1997.

[52] TuncayHarirolan ,Meryem OZ; CT angiography of renal arteries and veins: normal anatomy and variants; DiagnIntervRadiol;2011, 67-73;17. 